The final publication is available at Science Direct via http://www.sciencedirect.com/science/article/pii/S0148296316000916

\title{
Contingent factors affecting network learning
}

Linda D. Peters, Associate Professor of Marketing, Nottingham University Business School, Jubilee Campus, Nottingham, NG8 1BB, UK.

T: +44(0) 1158466602

F: +44(0) 1158466667

Linda.Peters@nottingham.ac.uk

Andrew D. Pressey, Reader, Birmingham Business School, University House, Edgbaston Park Road, Birmingham, B15 2TY, UK

a.pressey@bham.ac.uk

Wesley J. Johnston, CBIM Roundtable Professor of Marketing, J. Mack Robertson

School of Business, Georgia State University, USA wesleyj@gsu.edu

Research Paper

Submitted 15 November, 2014

Revised 11 August, 2015

Accepted 12 January 2016

Keywords: Temporary Organizations; Absorptive Capacity; Cognitive Consistency.

Acknowledgements: This work was supported by the British Academy (grant number SG101502). 


\title{
Contingent factors affecting network learning
}

\begin{abstract}
To increase understanding of the impact of individuals on organizational learning processes, this paper explores the impact of individual cognition and action on the absorptive capacity process of the wider network. In particular this study shows how contingent factors such as social integration mechanisms and power relationships influence how network members engage in, and benefit from, learning. The use of cognitive consistency and sensemaking theory enables examination of how these contingent factors influence the learning processes of two construction industry design teams embedded within more permanent home-organizational structures. A number of practical ways arise by which firms can facilitate organizational learning through their interactions with network partners. Enhancement of learning in and between organizations occurs when members are cognizant of the means by which they connect within a network to create shared meanings, and the way in which they forge ties and share expertise in the learning process they engage in.
\end{abstract}

Keywords: Learning in networks; Absorptive capacity; Cognitive consistency. 


\section{Introduction: learning in networks}

Business networks and their constituent actors are a key potential source of learning. Coverage of this topic, however, often fails to capture important dynamics in the learning of inter-firm collaborations by not recognizing that learning by a group of organizations may have distinct characteristics (Knight \& Pye, 2005). Biggemann, Kowalkowski, Maley, and Brege (2013) urge a refocus away from simple customer-supplier dyads to a network perspective that recognizes the interdependence of companies. A particular case of network interdependence is where groups of permanent organizations form what are termed 'temporary organizations'.

Temporary organizations are situations where individuals from different organizations collaborate on a task for a defined period of time (Bechky, 2006). Temporary organizations differ from other forms of company collaboration such as multi-project organizations (Räisänen \& Linde, 2004) and joint ventures because they have characteristics such as institutionalized termination and conflicting loyalties and tensions. The term 'temporary organization' is useful not because it represents a unique type of organizational form, but because it highlights two key features related to the interconnections between network members: that such projects are temporally bounded in nature, and form between rather than within more permanent organizational institutions.

The approach taken herein includes both the structural and configuration aspects (Burt, 1992) found in social network analysis and the notion of the individual as embedded within a wider network of institutions (Granovetter, 1985). Thus, “...organizations are collections of overlapping knowledge systems each of which may be embedded within a wider occupational community" (Araujo, 1998, p. 331). Therefore, the temporary organization is a network embedded within wider organizational and industry contexts (Granovetter, 1985). Embeddedness is a concept with a long tradition in organizational studies, stretching from Simon's (1962) view of complex systems as composed of subsystems that, in turn, have their 
own subsystems, through Granovetter's (1985) notion of cohesion between embedded relations, to embeddedness as a key feature of network dynamics (Chou \& Zolkiewski, 2012).

The relationship between the learning processes established in such temporary organizations (which sit alongside and within more permanent and established organizational forms) and the learning processes found in the larger and more permanent organizations of its members (i.e., their home organization, industry associations, or other joint industry projects) remains poorly understood. This relationship, at its core, highlights issues regarding how individual actors, through their cognitions and the acquisition of cognitive resources, undertake brokerage in these embedded networks to enhance social capital.

Holmlund (2012) highlights the need for further research focusing on the way in which ideas constrain and condition how resources connect and adapt within business networks. Strandvik, Holmlund, and Edvardsson (2012) argue for a focus on the logic of network participants (customers and suppliers), in particular the shift to a logic which focuses on who and what creates value for network participants.

This study has two objectives. First, to develop from both a theoretical and a practical standpoint a more nuanced understanding of the challenges faced in temporary organizational networks in terms of developing sustained cognitive structures and sharing new understandings between individuals. Second, to further understanding of the impact of individuals (particularly within a social context, i.e., the building of social capital) on organizational learning processes (i.e., absorptive capacity), and of how such capacities exist at different levels of analysis (Volberda, Foss, \& Lyles, 2010, p. 944-945). This research thus explores the impact of individual cognition and action on the absorptive capacity process of the wider network. The use of cognitive consistency and sensemaking theory allows examination of how contingent factors influence the learning processes of two construction industry design teams (i.e., temporary networks) embedded within more permanent home-organizational structures. 
The structure of the paper is a follows. First we begin by explaining the cognitive theoretical approach that will form the basis of our analysis. We then examine learning in networks from an absorptive capacity perspective. We follow this with a discussion of the case study methodology and present our findings in relation to both case studies. We then identify the mechanisms behind our observed findings. Finally, we offer conclusions and discuss the managerial implications of our study.

\section{Cognitive theory and learning in networks}

Knight and Pye (2005, p. 371) define network learning as “... learning by a group of organizations as a group. In this specifically network-centered view, changing network level properties, such as shared practices and processes, would indicate network learning". These authors also make a critical distinction between learning in different network contexts: network learning outcomes may occur across the wider network, whereas network learning processes are local (Knight \& Pye, 2005).

Learning in networks often means working within an embedded structure that may have very different features (such as time frames) and thus may represent very different types of relationships. A cognitive theoretical approach to understanding networks allows exploration of such relationships. Cognitive theoretical approaches, when applied to networks, focus on shared interpretations for message content, such as network goals and stories (Knight \& Pye, 2005). In business settings, the significance of these mental models, defined as a shared cognitive belief system or an interpretive scheme (Giddens, 1984) held by key actors (individuals, teams and/or companies), is that they filter the attention of managers and guide corporate decisions and behavior (Strandvik, Holmlund, \& Grönroos, 2014).

Sensemaking is one route to the formation of shared cognitive belief systems. Sensemaking is defined as those processes by which people seek to understand ambiguous, equivocal or confusing issues or events (Brown, Colville, \& Pye, 2015) and which acknowledges both 
discovery, invention and interpretation (Weick, 2006). Brown et al. (2015) note that many theorists are reluctant to place sensemaking processes within wider contexts (i.e., cultural, institutional, and organizational structures). Some researchers recognize that institutions may shape sensemaking (Bardone \& Secchi, 2009; O’Malley, Ritchie, Lord, Gregory, \& Young, 2009), although frequently limit its influence to the internalized cognitive constraints of individuals and fail to recognize that decision-making in situated contexts is in fact practical, deliberate, and the consequence of dynamic social and reflexive sensemaking processes (Brown et al., 2015).

Brown et al. (2015) suggest that there is scope for a fuller understanding of the distributed sensemaking of individuals and groups in (and between) organizations to make decisionmaking processes more reliable. This relationship is dualistic, in that human action and social context are inseparable (Bhaskar, 2008; Giddens, 1984). Tasselli, Kilduff, and Menges (2015) maintain that on the one hand the personality and cognitions of individuals shape the network positions they occupy and the network patterns they utilize, and on the other hand that the embedding network situations and patterning influence an individual's psychological state. Far from disputing the classical sensemaking view that individuals draw upon prior knowledge in order to reduce complexity and assign meaning to new information, this approach extends our understanding to the situated nature of cognition and its relationship not only to internal mental processes but also to embodied concrete experience, allowing us to understand how human thinking facilitates social functioning (termed embodied cognition; O’Malley et al., 2009). Thus, cognitive consistency is not restricted to internal mental processes or models alone. These internal processes and models filter the attention of managers and guide corporate decisions and behavior (Strandvik et al., 2014). Thus, cognitive consistency also informs managerial action (both individual and group). Members of a temporary organization may find themselves belonging to two non-overlapping cliques (groups of actors in which everyone has a direct tie to everyone else): one clique in their permanent home organization, and the other in 
their membership of the temporary organization. An individual belonging to these groups is likely to find attitudes and behaviors constrained to fit the demands of each respective group. Thus, individual decision-making is subject to the social control of co-clique members (Tasselli et al., 2015).

A cognitive approach to understanding social networks builds on the idea that if people define situations as real, their consequences are real. Thus, the representation of knowledge is dependent on brain structures involved in perception, action and introspection and not simply semantic interpretation and symbolic processing (O’Malley et al., 2009). In the field of social network cognition, the task of investigating perceptions of social networks as phenomena in their own right (rather than simply how individuals recall social interactions) has legitimacy (Tasselli et al., 2015). In particular, cognitive consistency may explain the mechanism by which individuals' fulfil their aspirations for consistency in their cognitions - a prime motivation for changes in beliefs, attitudes, and/or behaviors if these are not psychologically consistent (Festinger, 1957). This view translates in a network context as the extent to which a drive for consistency manifests in network membership, attitudes, and relations. In terms of decision-making, the organizational social environment affects the decision-maker in that the individual-organization interaction is defined in terms of a collectively shared interpretation (termed distributed cognition; Bardone \& Secchi, 2009). Thus, actions may reform beliefs and attitudes which may recursively alter further actions. This is a process of coherence-driven processing (Simon, Snow, \& Read, 2004), that enables confidence in decision-making by bringing the various pieces of the cognitive field into consonance (Simon \& Holyoak, 2002).

\section{Contingent factors affecting learning}

One way to understand learning is through the development of 'absorptive capacity'. Cohen and Levinthal (1990) use this term to capture the notion that learning in firms is more than the summative effect of the learning of the individuals in the firm, and that firms differ in their 
capabilities to learn by: (1) recognizing the value of new knowledge, and (2) acquiring, (3) assimilating, and (4) applying this knowledge to create business value. Researchers see managerial cognition as an important aspect of absorptive capacity research, as it is the ability and motivation of managers to absorb external knowledge, and to develop theories about the world around them, that strongly influences the absorptive capacity of the firm (Volberda et al., 2010).

It is not, however, simply the knowledge sharing and recognition aspects of individual cognition that is important in understanding absorptive capacity, for “ $\ldots$ at the organizational level routines, histories, stories, documentation procedures and know-how are important in creating a shared understanding of such knowledge" (Volberda et al., 2010, p. 935). Echoing this view, Lubatkin, Florin, and Lane (2001) state that the capacity to learn and jointly discover (unlike the capacity to absorb) requires a unifying vision. Thus absorptive capacity, as a learning process, involves the interplay of cognitions and actions.

Several contingent factors may enhance or inhibit all four of the absorptive capacity components (Todorova \& Durisin, 2007). These contingent factors provide a useful way in which to frame the broader social context in which both organizational and individual decisionmaking and learning takes place. This study attempts to explore how two of these contingent factors, social integration mechanisms and power relations, influence network members in terms of their engagement in learning processes and the building of absorptive capacity.

\subsection{Social integration mechanisms}

Social integration mechanisms facilitate connectedness and shared meanings between actors (Merali, 2000; Todorova \& Durisin, 2007), determining how knowledge is employed within networks. Social attachments in inter-organizational relations also provide a means of increasing absorptive capacity by reducing cognitive costs and efforts, as each partner is better acquainted with the needs of the other and so will seek to provide information to suit those 
needs (Malhotra, Gosain, \& Sawy, 2005). Thus, social integration mechanisms facilitate learning in that they draw actors together and serve as a source of network cohesion. However, the embedded knowledge and well-established capabilities and routines of firms may hamper the ability to identify and absorb new external knowledge (Todorova \& Durisin, 2007). Thus, traditional ways of working and thinking may blind participants to the opportunities present and inhibit learning in networks.

The first research question examines how the use of social integration mechanisms relates to learning activities. Learning in network contexts relies on the use of social integration mechanisms both to introduce new knowledge (which may challenge existing knowledge) and to help integrate this knowledge into existing schema. Therefore:

\section{P1: Where the use of social integration mechanisms allows the development of shared cognitions between network members it will have a positive influence on learning, allowing the network to develop greater cognitive consistency.}

\subsection{Power relations}

Power is a complex notion that receives much attention in the management literature. The definition of power posited by Mingers (2014) embraces a systems view of power relations which is appropriate to the exploration of both individual and network contexts in the present study. As Mingers notes: “...power is the ability to generate or cause a particular outcome to or with some other entity or system [original emphasis], within a particular context (or perhaps 'environment' in systems terms)" (Mingers, 2014, p. 72). Power relations influence the exposure to and the exploitation of new knowledge (Todorova \& Durisin, 2007), ultimately influencing the extent to which learning takes place.

Power relations may also affect learning through their influence on the development of social capital within networks (De Wever, Martens, \& Vandenbempt, 2005). Social capital - 
defined as the social context (i.e., social ties, trusting relations, and value systems: Tsai \& Ghoshal, 1998) facilitating the actions of individuals - establishes paths for knowledge transfer as well as reciprocal learning (Thibaut \& Kelley, 1959). Researchers infer the association between networks and knowledge transfer by observing the links between network structure and network performance (Reagans \& McEvily, 2003). In particular, researchers focus on the role of cohesion (the extent to which strong third-party connections surround a relationship) and range (the extent to which network connections span institutional, organizational, or social boundaries) as facilitators of knowledge assimilation and transfer in networks.

This approach relates directly to network structures and forms through structural holes, defined as gaps in connectedness between network members (Burt, 1992). However, structural connectedness alone cannot explain the development of social capital. The realization of potential social capital also depends on how individual differences combine with the strategies and roles that people develop for social networking (Tasselli et al., 2015). These individual attributes and motivations are the drivers of personal strategic approaches to power relations or personal strategies. Therefore, both the network structural forms and the personal strategic motivations of power relationships influence the exposure to and the exploitation of new knowledge, ultimately influencing the extent to which learning takes place and the development of social capital. Therefore the second research question examines how power relationships in the network influence its learning activities. Do power relations facilitate or constrain learning in networks, and how?

\section{P2: The development of social capital through both structural and personal power relations influences the extent to which learning takes place in the network.}

Presentation of these research questions in Fig. 1 provides a framework for exploration of the present observations to investigate learning processes in networks. 
Fig. 1. A framework for leaning processes in networks.

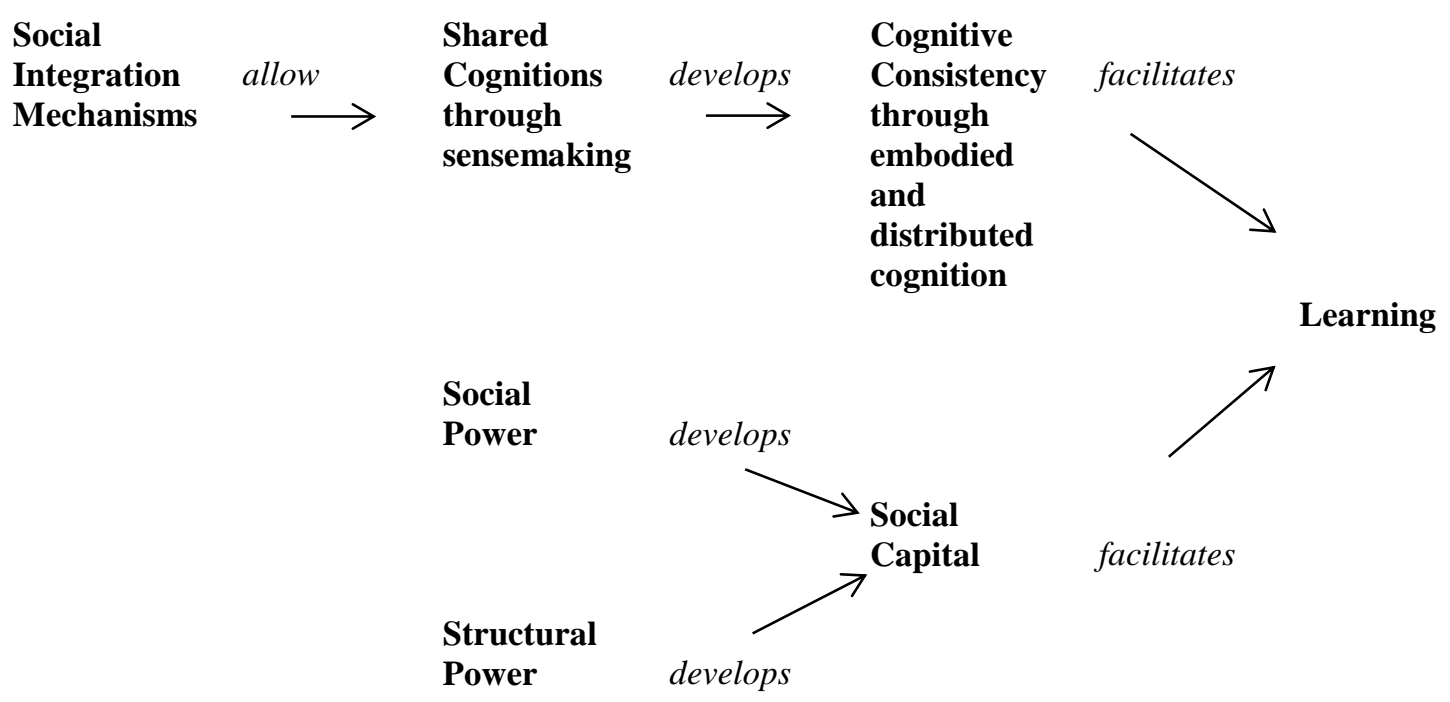

\section{Methodology}

Two case studies provide a means of inspiring new ideas in relation to understanding learning processes in networks (Siggelkow, 2007). These case studies are concerned with the delivery of large-scale construction projects in the UK. The construction industry is an interesting research context in which to understand learning in networks because it has: (1) low diffusion of new technologies and practices often due to adversarial relationships (Anderson \& Cook, 2004); (2) potential radical change of network relationships from project to project and loose network couplings, inhibiting the ability of members to form sustained cognitive structures that support learning (Dubois \& Gadde, 2002); and (3) short-lived site-specific project-based activity and uncertainty due to a lack of complete specification (Dubois \& Gadde, 2002).

Sampling of these construction projects is theoretical (Yin, 1994), based on the opportunities they provide to explore learning in both the temporary organization (i.e., the design team formed to complete the projects) and the more permanent organizations from which the design-team members originated. Access to the two construction projects was gained 
via the assistance of an industry expert (a senior director in a major UK construction company), who was a personal contact of one member of the research team, and who was able to advise on suitable projects to examine based on industry contacts and experience.

Case study 1, OfficeProject, is a UK project creating office space and conference and training facilities. The second case, PowerProject, relates to the construction of a combined heat and power plant (CHP) in the UK for a large-scale institutional user. Table 1 summarizes key features of each case and details of the management teams, which were of equal size. Some team members participated in both projects. 


\section{Table 1}

Summary of data.

\section{Case summaries}

$\begin{array}{ll}\text { Value } & \begin{array}{l}\text { Case } 1 \text { OfficeProject } \\ £ 8.5 \text { million }\end{array} \\ \text { Purpose } & \begin{array}{l}\text { Office accommodation and conference/training } \\ \text { facilities }\end{array} \\ \text { Supplier } & \begin{array}{l}\text { A leading construction, development and services } \\ \text { group in the UK. The group employs } 11,400 \\ \text { people worldwide and has an annual revenue of } \\ £ 2.1 \mathrm{bn} .\end{array}\end{array}$

Customer Training and Education Provider
Level of Medium, new variant of energy-efficient risk construction technology used previously by this client in other buildings.

Planning 9 months in planning; data collected over the 24time frame month construction period.

\section{Case 2 PowerProject \\ $£ 8$ million}

Combined heat and power (CHP) generation

A leading construction and regeneration group in the UK. The group employs over 8,500 people and has an annual revenue of over $£ 2,548 \mathrm{~m}$.

Large-scale site with district heating system for approximately 30 buildings.

High, if successful will be the first working CHP plant utilizing this form of energy production technology in the UK.

3 years in planning; data collected over the 24-month construction period.

\section{Respondent demographics}

\begin{tabular}{|c|c|c|c|c|c|}
\hline & $\begin{array}{l}\text { Client Team } \\
\text { (e.g., Project } \\
\text { Director, Project } \\
\text { Administrator }\end{array}$ & $\begin{array}{l}\text { Client Team } \\
\text { Representatives } \\
\text { (e.g., Project Managers } \\
\text { and their Quantity } \\
\text { Surveyor) }\end{array}$ & $\begin{array}{l}\text { Design Team } \\
\text { (e.g., Architect, } \\
\text { Mechanical and } \\
\text { Electrical } \\
\text { Engineers, } \\
\text { Structural } \\
\text { Engineers) }\end{array}$ & $\begin{array}{l}\text { Other } \\
\text { Specialists } \\
\text { (e.g., Clerk of } \\
\text { Works, Landscape } \\
\text { Specialists, Acoustic } \\
\text { Specialists) }\end{array}$ & $\begin{array}{l}\text { Contractor } \\
\text { Team } \\
\text { (e.g., Project } \\
\text { Managers, and their } \\
\text { Quantity Surveyor) }\end{array}$ \\
\hline OfficeProject & 3 & 3 & 4 & 5 & 3 \\
\hline PowerProject & 3 & 1 & 5 & 5 & 4 \\
\hline
\end{tabular}

The data collected for this study consist primarily of 45 in-depth semi-structured interviews and two focus groups conducted with design-team members over a period of 24 months. In addition, researchers attended 14 design-team progress meetings (eight for OfficeProject and six for PowerProject) in which they collected official progress documents and made notes. The researchers coded the transcribed interview data using AtlasTI v6 software, following the coding procedure outlined by Strauss and Corbin (1998). The components of absorptive capacity (recognition of new knowledge, acquisition, assimilation, transformation and exploitation) formed the initial coding framework. The researchers examined the data for co- 
occurrence of the two contingent factors of learning (social integration mechanisms and power relations) with the components of absorptive capacity development.

This study adopts a retroduction approach (Bhaskar, 2008). This approach describes the use of an imaginative leap to produce some theory or explanation to account for an unexpected observation. It is neither an induction from an observed phenomenon, nor is it a deduction from some generalized rule. Retroduction looks for the underlying mechanisms that generate events. Such mechanisms have causal powers, or tendencies, to bring about changes in the world (Mingers, 2014). Retroduction is the point where novelty, innovation and creativity enter the scientific method, and helps to provide an explanation for events, not simply a re-description of them (Mingers, 2014). It starts with some accepted happening or occurrence and asks: What must the world be like for this to occur or to be intelligible (Bhaskar, 2008)?

Three aspects of validity (internal, construct and external) ensure rigor in data collection and analysis. The first, internal (or logical) validity refers to the plausibility and credibility of research results and conclusions (Yin, 1994; Cook \& Campbell, 1979). Two approaches control internal validity: the collection of multiple perspectives through interviewing actors at different points in the network, and at different points in time (Yin, 1994); and a process of pattern-matching (Denzin \& Lincoln, 1994; Eisenhardt, 1989) by comparing with empirical patterns established in previous studies (e.g., Dubois \& Gadde, 2002) and among the interviewed participants.

Construct validity refers to "...the quality of the conceptualization or operationalization of the relevant concept" (Gibbert, Ruigrok, \& Wicki, 2008, p. 1466) or whether the study investigates what it purports to be investigating. To help ensure construct validity and to aid triangulation (Denzin \& Lincoln, 1994), different data-collection strategies allow different perspectives of absorptive capacity that affects knowledge within networks: in-depth interviews, minutes of meetings and attendance at meetings. 
External validity refers to the generalizability of a study's findings (McGrath \& Brinberg, 1983). Although case studies and interpretivist methodologies cannot provide statistical generalization, this property does not mean that they are "...devoid of generalization" (Gibbert et al., 2008, p. 1468). Case studies can strive for analytical generalization, that is, generalization to theory using empirical evidence (Eisenhardt, 1989). Eisenhardt (1989) suggests that the use of multiple case studies facilitates theory development. Although the present study uses only two case studies, cross-case comparison remains possible.

Reliability refers to the extent that subsequent researchers replicating the study produce similar insights (Denzin \& Lincoln, 1994). Gibbert et al. (2008) suggest that transparency and replication are two primary methods that aid reliability. The use of a case study protocol allows control of transparency, while control of replication arises through creation of a case study database. For the present study, the case study protocol outlines how the study was conducted and the case study database includes transcribed interviews, minutes of meetings and observations of meetings in order to facilitate case study replication (Leonard-Barton, 1990).

\section{Findings}

In section two we defined learning in networks, and acknowledged that while learning outcomes may happen across the wider network, learning processes are often local. We focused on sensemaking and shared cognitions not simply as a mental process, but as processes that could guide behaviour and facilitate learning because cognition is embodied and distributed. In section three we highlighted two contingent factors that may facilitate or constrain leaning; social integration mechanisms (which impact the development of shared cognitions between network members) and power relations (which impact the development of social capital). We now examine the data and posit what we consider to be the underlying causal mechanisms in relation to social integration mechanisms and power relations that may have generated the events observed. 


\subsection{Case 1 (OfficeProject)}

The OfficeProject remit was to create office space and conference and training facilities. Construction work began on-site after a planning stage lasting approximately nine months. The project design team involved 18 members from nine different organizations.

\subsubsection{OfficeProject social integration mechanisms}

In the project meetings, extensive use of technical drawings and diagrams allowed building a consensus of meaning between the different technical disciplines by ensuring correct understanding of the interpretation (or framing) of information. This approach provided an agreed blueprint for construction and an audit trail of design alterations. One respondent expressed the value of this process of collective sensemaking as: "There is no substitute for face-to-face, all sitting round a table with a drawing or whatever." This interaction allowed distributed cognition (i.e., building a collectively shared interpretation) and coordinating and refining of the exploitation of their knowledge. Individuals, however, differed in their approach to the envisioning of this information. Often, this difference was because their professional training created embedded knowledge and well-established capabilities that constrained their openness to the value of new knowledge, and its acquisition, and hampered new ways of looking at information (knowledge assimilation and transformation). For example, the architect stated that the engineers could not visualize the actual experience of being in the building.

In addition to envisioning, enacting was a vital part of their communication behavior. One of the primary motivations for holding monthly face-to-face progress meetings was to allow individuals to enact their understanding through interaction (i.e., facilitating social functioning through embodied cognition). This enacting allowed them to exploit their knowledge in new and novel ways, and to find innovative solutions to issues and problems. Respondents saw both formal and informal settings for enacting as important. While the more formal progress meetings gave everyone the opportunity to verify their own understandings with those of 
others, the informal site meetings allowed more practical and often very specific problemsolving. The architect in particular welcomed involvement with the contractor and subcontractors on site, and described how the different mindsets of the contractor (practical) and himself (artistic) could come together in a focused way through such interactions: "It feels family friendly, like a conductor and an orchestra ... You would think we would not get on as he is trying to save money and I am trying to spend it ... But on this project we get on and all work together. It is one of the best working teams I have been on in a long time". In addition, the contractor organized a charity project where the design-team members spent a day building a nature walk for a local school. This team-building day helped to build stronger personal relationships and a greater sense of common purpose on the OfficeProject build.

Thus, communication behaviors such as enacting and envisioning are causal mechanisms that help to shape the representation of the task (i.e., help to form shared cognitions through sensemaking) and allow for its completion by addressing issues in convergence and divergence of understanding among network members (i.e., developing cognitive consistency through embodied and distributed cognition), allowing coordination and refining of knowledge.

\subsubsection{OfficeProject power relations}

Respondents recognized that within temporary organizations there can be problems regarding “...defending your expertise” on projects. The structural engineer on OfficeProject stated that: “...you can only go so far as a team, but on site, and at a greater level of detail, decisions may be made by individuals." Thus personal integrity, both given and received, is a cogent feature in power relations between team members and a factor in the exploitation of knowledge.

The importance of cohesion (the extent to which strong third-party connections surround a relationship) and range at the stage where the contractor becomes part of the temporary organization is particularly crucial. This criticality is because it changes the power structures of 
the team. The contractor describes this stage as having a tripartite structure, with the client and user group (those who will inhabit and use the building) as members of more permanent organizations on the one hand, and the contractor and their supply chain on the other. Inbetween these two networks sits the third element of the tripartite structure: the client team (e.g., the architect, structural and mechanical/electrical engineer). This structure places increased importance on the Project Administrator and Project Manager, who act as cohesive agents between these networks. Their roles help knowledge acquisition and assimilation in the temporary organization.

Although there are some direct linkages between the client team and the contractor, it is the Project Administrator and the Project Manager who forge ties between the members and bring cohesion to the temporary organization. Thus, they are instrumental in translating client wishes into construction activities. The relative complexity and greater range found in their individual network configurations may provide ways to challenge established practices, but also places them as key integrators in bringing cohesion to the temporary organization overall. Without them, the limited cohesion among the client, the contractor, and the design team would inhibit learning through knowledge acquisition and assimilation.

One design-team member, reflecting on the progress of the project, suggested that greater involvement by the risk and sustainability manager for the client company could have been useful in relation to knowledge assimilation. This lack of involvement led to decisions by the Project Administrator and the relevant design specialists to remove features related to energy efficiency from the intended design. They did not understand the importance of these features to the overall design.

Once the Risk and Sustainability Manager became aware of this decision, and because he considered these features to be key to the sustainability of the design, he approached the clients' Project Board directly who then revised the budget to allow for inclusion of these design features. The manager exploited his superior knowledge of these design features to 
provide feedback to the client that their loss would negatively impact the performance of the building. This strategy caused some ill-feeling on the part of the project team, who did not feel consulted about the problem prior to the manager approaching the Project Board.

In describing his involvement with the project, the Risk and Sustainability Manager described his role as one of a boundary spanner between the client and the project team: " $I$ seem to flit between the two". Thus, the manager viewed these networks as three highly disaggregated constituents (the client, himself, and the project team). This view ignores the richness of ties that characterized the network relationships of the Project Manager and Project Administrator. Rather than using power relations to help transform the understanding of the team members, the manager exploited his own knowledge by approaching the client directly with his concerns and seeking to legitimize his views outside of the project team. It is possible that a greater sense of inclusion and participation with the project team might have enhanced the boundary-spanning role of this manager in more positive ways.

Thus, respecting and defending expertise offers causal mechanisms that allow members in the temporary organization to exert social power through their specialist knowledge and to maintain their integrity not only personally, but as representatives of their permanent home organizations. Second, the causal mechanism of forging ties between actors in the network shifts with the role of the temporary organization. The range increases to include a wider variety of network members from differing specialisms, and the focus for cohesion falls on the Project Administrator and Project Manager who must bridge client, user, and contractor interest groups by exerting their structural power.

\subsection{Case two (PowerProject)}

The PowerProject remit was to build a combined heat and power (CHP) plant for a largescale institutional user which would eventually provide up to $90 \%$ of the client's electricity 
requirements. On-site construction began after a planning stage of approximately three years. The project design team involved 18 members from 11 different organizations.

\subsubsection{PowerProject social integration mechanisms}

Unlike the OfficeProject build, the PowerProject temporary organization operated in two distinct phases. The first phase involved construction of the building (often referred to by the design team as 'the shell' or 'the shed'). The second phase involved installation of the powergeneration equipment (referred to as 'the fit-out'). This structure provided a number of issues for managers coordinating the project, particularly in relation to enactment as a social integration mechanism. The Project Manager coordinated work between the two phases through regular face-to-face (monthly) design-team meetings and implemented a system of signing-off at each stage of the design and construction process; this process made co-location desirable for the companies involved. On this project the shell-construction design-team members clustered in three reasonably close locations: one cluster at the client site (the site of the build); another cluster approximately 5 miles away; and a third cluster approximately 70 miles away. Attendance at monthly progress meetings and interim site meetings for building the shell was good and helped to facilitate social functioning through embodied cognition. Colocation helped to make enactment (through attendance) at these meetings possible.

The lead contractor for the power-generation equipment fit-out, however, originated several hundred miles from the project. His specialist expertise in this power-generation technology made his employment necessary (for knowledge acquisition). Nevertheless, the Project Administrator for the first phase of the project expressed concern about this potential lack of availability and resulting distanced communication making knowledge assimilation and transformation harder due to a lack of enactment. The Project Administrator noted that: "It's the guy in Devon. He is tripping around the UK a significant amount. And most of his contact is by telephone. He designs something, he gives it to his CAD operator in his office who then 
draws it up and he emails it. So most of this process is by email and telephone. We've managed to get him on about three occasions to meet the Design Team and discuss but I think that is vulnerable because my experience tells me unless you're sitting as we are now face-to-face ... you would've had an overview of it but you certainly didn't understand the detail of that." He recognized that enactment through face-to-face communication is important, with knowledgeacquisition methods such as detailed plans and drawings in place: "It helps link understandings between people, and the lack of it is one reason why the project is so late." The Project Administrator termed it a "lack of intimate design review process" and felt that this lack of enactment made them vulnerable. Thus, tools used to facilitate envisioning, such as technical drawings and specifications, do not substitute for enacting when it comes to knowledge assimilation, transformation, and utilization.

The lack of these social integration mechanisms (both envisioning and enacting) between the shell and the fit-out teams meant that uncertainty was a common feature of the design process. Frustrations arose in those designing and building the shell when contending with questions left unanswered (a lack of enactment) and with the fit-out team who at times did not seem to understand the implications of missing information (a lack of envisioning), making distributed cognition (i.e., building a collectively shared interpretation) difficult. The geographical distance between key members of the two teams compounded this frustration as it prevented the attendance of the lead fit-out contractor at the monthly progress meetings of the shell-design team: an example of the real problems that a lack of social integration mechanisms can precipitate.

Other forms of knowledge dissemination allowed the permanent organizations to share learning across projects. For one organization, this sharing of information took the form of an intranet with technical manuals written by individuals on the project and containing their contact details. However, as the engineer from this organization noted: “...there are sector champions in [the organization]. So there are certain people who look after certain sectors. So 
often if you come up with a problem, you can get hold of those people and say "Right, who in the business has done one of these before?" And they'll give you a phone number and you can phone them and talk to them. So that's word of mouth, which is I think better sometimes than anything written down because whatever you write down, the whole truth isn't there anyway. So a lot of it is just talking to the other guys in the business...". Here, envisioning and enacting supplement the codified information in the permanent organization, facilitated by the identification of individuals who have sector-specific expertise. It is this expertise and experience that makes them valuable tools in knowledge sharing, as they provide the context for the codified knowledge within the organization and help form interpretive schemes.

Like OfficeProject, enacting and envisioning helped to shape the representation of the task and allow for its completion. However, geographical distance made enactment difficult, and limited the usefulness of envisioning tools such as technical drawings. This lack of accompaniment of such tools by processes of enacting hampered building convergence of meaning. These problems, particularly in phase two of the project, limited convergence and divergence of understanding through embodied and distributed cognition between network members, and the extent to which knowledge could be coordinated and refined.

\subsubsection{PowerProject power relations}

Pressures occurred not only within the temporary organization and among the permanent organizations involved, but also from external sources. As this power plant was sited close to residential buildings, the local authorities insisted on stringent sound restrictions. The building could not exceed sound levels measured on the site at 2 am prior to operation. Thus the largescale 'shed' now had to act as a sound booth.

This constraint caused the shell design team to - in their own words - "over engineer" the solution. Working with the contractor they created new ways to guarantee sound-emission levels. They needed to respect the expertise, power, and authority of the local planning 
department and meet their requirements, and to find ways to defend their own power and expertise to the planners. One way to achieve this balance was to exploit their knowledge by conducting sound tests on a model of the building to demonstrate to the planners that they could meet these requirements. As one of the engineers commented: “... testing on that smaller scale gave enough confidence that actually it was going to be okay." While this requirement placed design constraints on the build, the respondents commented on the positive effects of this kind of cooperation in the temporary organization, and how it improved power relations by building respect for each member's expertise.

This positive approach did not extend to the second (fit-out) phase of the build. As one team member noted: "We have a design team and a client and we can then say that the fit-out team was quite well apart. We can say that they didn't really want to be part of that." The resulting fragmented power relations on the project limited its range of inclusion. This result was in part the personal choice of the Project Manager for the fit-out phase, who held definite views about how the project should be run: "A group of ten or fifteen people all supposedly being experts with an independent opinion each beyond their qualified skill range going into a melting pot that contributes to a decision outside of their disciplines to an obvious degree. I really think it is the wrong way to manage a project. You need strong leadership and you need a smaller group of dedicated individuals. Not a very large group doing small pieces that really in my view has no clear control. I don't believe our construction activity has full control in the manner that I would demand it to be achieved."

As with OfficeProject, two main causal mechanisms are at work. Respecting and defending expertise allowed members in the temporary organization to exert social power through their specialist knowledge and to maintain their integrity not only personally, but as representatives of their permanent home organizations. Constructing a scale model to test sound emissions helped to establish credibility for the temporary organization with outside parties, such as local authorities, who held strong and legitimized power to stop the construction. However, the 
questionable extent to which the Project Administrator on the second phase of the build forged ties in the temporary organization limited his structural power.

\section{Discussion: mechanisms for learning in networks}

To consider the findings and causal mechanisms identified in Section 5 in relation to the two contingent factors of absorptive capacity (social integration mechanisms and power relationships) and their influence on learning in networks, Table 2 summarizes two key research questions and their associated propositions, the mechanisms related to aspects of learning, and the associated learning benefits.

\section{Table 2}

Contingent factors of learning in temporary organizations: summary of findings

\section{Contingent factors}

RQ1: How does the use of social integration mechanisms relate to the learning activities of network members? Do social integration mechanisms positively enhance learning? If so, then what are the social integration mechanisms that facilitate this, and how?

P1. Where the use of such social integration mechanisms allows the development of shared cognitions between network members it will have a positive influence on learning, allowing the network to develop greater cognitive consistency.

\section{Mechanisms facilitating learning Learning benefits}

\section{Communication behaviors of} enacting and envisioning

- Shared cognitions through sensemaking by framing problems and forming interpretive schemes

- Developing cognitive consistency

- Continuity of intentions and actions

- Cognitive consistency through embodied and distributed cognition by finding solutions and conveying information

\section{RQ2: How do power relationships} in the network influence the learning activities of members? Do power relations facilitate or constrain leaning, and how?

P2. The development of social capital through both structural and personal power relations influences the extent to which learning takes place in the network.

\section{Respecting and defending expertise}

- Establishing social power through credibility within and between networks

\section{Forging ties between actors}

- Establishing structural power through actors acting as knowledge
- Developing social capital within and between networks

- Exposure and exploitation of resources through network cohesion and the range of the network horizon 
brokers by providing a

bridge between

unconnected actors

\subsection{Social integration mechanisms}

Our first proposition posited that where the use of social integration mechanisms allows the developing of shared cognitions between network members it will have a positive influence on learning, as they allow the network to develop greater cognitive consistency. In support of this we identified two mechanisms that acted as facilitators for learning in relation to the social integration mechanisms employed. Both envisioning and enacting communication behaviors influence cohesion and learning, and affect the continuity of intentions and actions through forming common interpretive schemes.

\subsubsection{Communication behaviors of envisioning}

In the design team meetings for both projects, envisioning and the framing of understanding through the use of technical drawings and progress reports are important tools to convey tacit understanding and to gain cognitive consistency. The use of drawings is transformative, in that drawings facilitate envisioning the results of actions. This envisioning, however, is bounded by external factors such as training and professional background, which as Todorova and Durisin (2007) note, may hamper the ability to identify and absorb new knowledge.

The capacity jointly to learn and discover requires a unifying vision (Lubatkin et al., 2001) and a collectively shared interpretation that helps to define individual-organization interaction (Bardone \& Secchi, 2009). Convergence, however, need not be complete in order to facilitate understanding and guide action. Giddens (1984) describes this scheme as interpretive, and sees its role as helping individuals to share in a common stock of knowledge without the assumption of common meanings and values which are somehow - at the level of the organization - identical and replicable across space and time (Boland, 1996). Facilitating 
continuity of intentions and actions on projects that span organizational and professional boundaries means that the development of interpretive schemes is important. These interpretive schemes allow for sufficient flexibility in understanding between the members of a network, helping to ensure continuity of intention and action. Thus communication behaviors of envisioning appear to support a shared sense of team goals, and may help ensure that project outcomes are as intended.

\subsubsection{Communication behaviors of enacting}

Members of the temporary organization could not only envision and interpret drawings, but also manipulate and change them in ways that made their meaning less ambiguous. Thus, such objects are not simply abstract mental structures, but in fact enact cognitive performance that “... can be viewed as the result of smart interplay between humans and the environment" (Bardone \& Secchi, 2009, p. 191). Substantial informal, as well as formal, communication took place between the temporary organization members. This enactment allowed not only faster progress on the builds, but also helped to integrate diverse understandings and solve problems. This situation reflects a distributed cognition view of the cognitive role of external resources, in that they help shape the representation of a task so as to transform difficult tasks into simpler ones (Bardone \& Secchi, 2009). Often, immediately following a formal design-team progress meeting, individuals would go on-site and discuss issues arising from the meeting, thus transferring enacting from a formal to an informal setting. By situating their enacting on the building site itself and engaging with the activities of the build, they could overcome any limitations or misunderstandings arising from the meeting where envisioning was limited to the use of communication tools such as drawings.

In the absence of enactment, as seen between the two distinct phases of the PowerProject, cohesion suffered and uncertainty became a normal feature of project interactions in both the temporary and permanent organizational networks. Different interpretations of technical 
drawings by different team members meant that one of the most powerful and effective unifying communication tools for temporary organization members was often the building itself. Thus, both enacting and envisioning can be situational and context dependent.

The importance of the charity-project away day on OfficeProject demonstrated how enacting activities unify temporary organization members and help to form commonly held interpretive schemes. These social relationships acted as powerful facilitators for the continuity of intentions and actions on this project. The lack of social integration mechanisms during the second phase of PowerProject meant that much of the knowledge transformation activities, which help firms to develop new perceptual schema or changes to existing processes (Todorova \& Durisin, 2007), focused on incomplete knowledge acquisition and uncertainty in knowledge assimilation.

Therefore, in relation to the first research question, social integration mechanisms such as enacting and envisioning help to maintain continuity of project intentions and actions (i.e., cognitive consistency through embodied and distributed cognition), by assisting in developing shared cognitions between temporary organization members.

\subsection{Power relationships}

Our second proposition posited that the development of social capital through both structural and personal power relations would influence the extent to which learning takes place in the network. In support of this we identified two mechanisms act as facilitators for learning in temporary organizations in relation to power relationships. These are respecting and defending expertise, and forging ties. These mechanisms provide the benefits of building social capital within the network, and establishing network characteristics such as cohesion and range.

\subsubsection{Respecting and defending expertise}


Several respondents raised the issue of defending both personal and professional expertise and how this requirement reflected power relations within the team. In relation to professional expertise, the temporary organization members elicited and respected different points of view: each member had the role of providing specific expertise in their area. Sensemaking tools (such as drawings, and sometimes site visits) functioned to make clear the implications of actions and decisions from a multitude of perspectives. This property could, however, lead to the need to reconcile and accommodate competing perspectives. For example, OfficeProject required the acoustics engineer and the structural engineer to collaborate given that the sound insulation normally placed on the ceiling - would compromise its thermal insulation.

\subsubsection{Forging ties}

Individuals may seek to enhance their power within a network by forging ties with two or more unconnected others, thus creating indirect ties between the people with whom they are linked (Burt, 1992). Network position allows actors (e.g., the Project Administrator) to act as knowledge brokers in temporary organizations. Thus network position infers power and acts as a mechanism for learning. This outcome is because such positions help to generate actor interests as perceptual norms and feelings, and because network linkages enable and constrain the flexibility, autonomy, and consequently the effectiveness of organizational members (Burt, 1992).

Burt (1992) maintains that prior experience with networks containing structural holes may make individuals quicker to learn brokerage opportunities to build coalitions in the network. They may have a higher likelihood of seeing structural holes and understanding the benefits that bridging such gaps brings (Tasselli et al., 2015). This propensity helps to embody social capital and to link individual and collective learning (Merali, 2000). In fact, such experience would reinforce the role of the Project Manager and the Project Administrator as one of forging ties that connect knowledge from the client in terms of value sought with the actions and 
capabilities of the design team and the contractor in terms of making that value a reality (i.e., knowledge exploitation). Without them, both the client and the other temporary organization members might not be able to identify and appreciate how to translate knowledge into value.

Therefore, in relation to the second research question power relationships influence learning activities firstly by establishing the recognition of expertise and integrity amongst temporary organization members (i.e., social power), and secondly by altering the exposure to and exploitation of resources which direct the development of social capital within temporary organization relationships (i.e., structural power).

\section{Conclusions and implications}

The purpose of this study is to understand how contingent factors such as social integration mechanisms and power relationships influence the learning of participants in networks. These contingent factors provide a useful way to frame the social context in which both organizational and individual decision-making and learning takes place, and thus help to establish a framework for understanding the situatedness of individual decision-making within broader institutional and structural contexts.

One practical objective is to develop a more nuanced understanding of the challenges faced in temporary organizational networks (because of their institutionalized termination and conflicting loyalties and tensions) in terms of developing sustained cognitive structures and sharing new understandings between individuals. The evidence underlines the importance of social integration mechanisms such as the communication behaviors of envisioning and enacting. These mechanisms allow the temporary organizations in particular to develop a shared language through sensemaking tools such as technical drawings and industry standards, and to enact understanding in face-to-face meetings, which helps to facilitate learning through developing shared cognitions. However, this envisioning could also hamper the ability to 
identify and absorb new knowledge though routines and frames of reference adopted as part of their professional training and background.

Enactment also plays a critical role in network learning in that it helps shape the representation of tasks to enable their easier execution. The building itself became a powerful communication tool for the enactment of understanding between network members. Both envisioning and enactment help in the formation of interpretive schemes through the establishment of a shared framing of knowledge and information by network partners across organizational and professional boundaries, and both are critical in learning as they help to ensure continuity of intentions and actions through embodied and distributed cognition. Seemingly minor or unrelated tasks, such as visits to other projects or social communal tasks can have disproportionate effects on forming interpretive schemes and facilitating learning.

In addition, power relationships influence exposure to, and exploitation of, new knowledge. The extent to which actors defend their expertise, respect the expertise of others, and forge ties with other actors within networks has implications for the degree to which social capital develops and learning can take place. Using sensemaking tools not only facilitates social integration, but sometimes reconciles and accommodates competing perspectives. Thus, the extent to which network members actively pursue the building of social capital and facilitate exposure to and exploitation of resources through their cohesion and range of connections with their network partners influences the ability to facilitate knowledge transfer in the network.

This study offers a number of useful implications for managers. Managers should utilize social integration mechanisms, both formal and informal, to facilitate sensemaking and the development of interpretive schemes that support continuity of intentions and actions. To achieve this outcome they could actively develop new and innovative ways of envisioning (i.e., developing new software tools or using interactive technologies to support intranets and knowledge management systems) and enacting (i.e., engaging in non-task-related projects with third parties such as charities, or physically taking discussions outside the office onto site to 
stimulate new insights). In addition, recognizing the value of professional expertise and enhancing respect through awards, training, and cross-discipline learning forums could have important positive effects on learning. Helping network members to forge ties, identifying key individuals in networks that act to bridge structural holes and supporting these individuals in extending and leveraging their network relations would also bring learning benefits to the network.

These findings provide a number of useful directions for future research. Firstly, research in other (contrasting) industries could shed light on any industry-specific social integration mechanisms and power dependencies. To extend understanding of learning in networks researchers could apply alternative network-related theories to those utilized herein (e.g., contagion or homophily theory), as well as drawing upon other literatures (e.g., collaborative learning). Questions such as: "What happens to the knowledge generated in the temporary organization when the project finishes?"; "How should organizations determine who the 'right' network partners are in the absence of prior experience?"; and "How can shared interpretive schemes benefit future network applications?" are worth consideration.

In conclusion, learning in networks can be significantly enhanced when members are cognizant of the means by which they connect within a network and create shared meanings (social integration mechanisms), and the learning process they engage in (power relationships).

\section{References}

Anderson, P., \& Cook, N. (2004). Dynamic innovation strategies and stable networks in the construction industry: implanting solar energy in the Sydney Olympic Village. Journal of Business Research, 57, 351-360.

Araujo, L. (1998). Knowing and learning as networking. Management Learning, 29(3), 317336. 
Bardone, E \& Secchi, D (2009). Distributed cognition: A research agenda for management. in MA Rahim (ed.), Current topics in management: Organizational behavior, performance, and effectiveness 14,183-207. Transaction Publishers, New Brunswick, $\mathrm{NJ}$,

Bechky, B.A. (2006). Gaffers gofers and grips: role-based coordination in temporary organizations. Organization Science, 17(1), 3-21.

Bhaskar, R. (2008). A Realist Theory of Science (3rd edition). London: Verso.

Biggemann, S., Kowalkowski, C., Maley, J., \& Brege, S. (2013). Development and implementation of customer solutions: A study of process dynamics and market shaping. Industrial Marketing Management, 42, 1083-1092.

Boland, R.J. (1996). Why shared meanings have no place in structuration theory: a reply to Scaperns and Macintosh. Accounting Organizations and Society, 21(7-8), 691-697.

Brown, A., Colville, I., \& Pye, A. (2015). Making sense of sensemaking in Organization Studies. Organization Studies, 36(2), 265-277.

Burt, R.S. (1992). Structural holes: the social structure of competition. Cambridge MA: Harvard University Press.

Chou, H., \& Zolkiewski, J. (2012). Decoding network dynamics. Industrial Marketing Management, 41(2), 247-258.

Cohen, D.M., \& Levinthal, D.A. (1990). Absorptive Capacity: a new perspective on learning and innovation. Administrative Science Quarterly, 35, 128-152.

Cook, T. D., \& Campbell, D. T. (1979). Quasi-Experimental Design: Design and Analysis Issues for Field Settings. Skokie, IL: Rand McNally.

De Wever, S., Martens, R., \& Vandenbempt, K. (2005). The impact of trust on strategic resource acquisition through interorganisational networks: Towards a conceptual model. Human Relations, 58, 1523-1543. 
Denzin, N. K., \& Lincoln, Y. S. (1994). Handbook of Qualitative Research. Thousand Oaks. CA: Sage.

Dubois, A., \& Gadde, L. (2002). The construction industry as a loosely coupled system: implications for productivity and innovation. Construction Management and Economics, 20, 621-631.

Eisenhardt, K. M. (1989). Building theories from case study research. Academy of Management Review, 14(4), 532-550.

Festinger, L. (1957). A Theory of Cognitive Dissonance. Stanford CA: Stanford University Press.

Gibbert, M., Ruigrok, W., \& Wicki, B. (2008). What passes as a rigorous case study? Strategic Management Journal, 29, 1465-1474.

Giddens, A. (1984). The constitution of society: outline of the theory of structuration. Chicago: Polity Press.

Granovetter, M. (1985). Economic action and social structure: The problem of embeddedness, American Journal of Sociology, 91(3), 481-510.

Holmlund, M. (2012). Interactive resource development in new business relationships: a commentary essay. Journal of Business Research, 65, 218-219.

Knight, L., \& Pye, A. (2005). Network learning: An empirically derived model of learning by groups of organisations. Human Relations, 58(3), 369-392.

Leonard-Barton, D. (1990). A dual methodology for case studies: synergistic use of a longitudinal single site with replicated multiple sites. Organization Science, 1(3), 248266.

Lubatkin, M., Florin, J., \& Lane, P. (2001). Learning together and apart: A model of reciprocal interfirm learning. Human Relations, 54, 1353-1382. 
McGrath J. E., \& Brinberg D. (1983). External validity and the research process: a comment on the Calder/Lynch Dialogue. Journal of Consumer Research, 10(1), 115-124.

Malhotra, A., Gosain, S., \& Sawy, O. (2005). Absorptive capacity configurations in supply chains: gearing for partner enabled market knowledge creation. MIS Quarterly, 29(1), $145-187$.

Merali, Y. (2000). Individual and collective congruence in the knowledge management process. Strategic Information Systems, 9, 213-234.

Mingers, J. (2014). Systems Thinking, Critical Realism and Philosophy: A confluence of ideas. Oxon: Routledge.

O’Malley, A. L., Ritchie, S. A., Lord, R. G., Gregory, J. B., \& Young, C. (2009). Incorporating embodied cognition into sensemaking theory: A theoretical integration of embodied processes in a leadership context. Current Topics in Management, 14, 151-182.

Räisänen, C., \& Linde, A. (2004). Technologizing discourse to standardize projects in multiproject organizations: hegemony by consensus? Organization, 11(1), 101-121.

Reagans, R., \& McEvily, B. (2003). Network structure and knowledge transfer: the effects of cohesion and range. Administrative Science Quarterly, 48, 240-267.

Siggelkow, N. (2007). Persuasion with case studies, Academy of Management Journal, 50(1), 20-27.

Simon, H. (1962). The Architecture of Complexity. Proceedings of the American Philosophical Society, 106(6), 467-482.

Simon, D., \& Holyoak, K. (2002). Structural dynamics of cognition: from Consistency theories to constraint satisfaction. Personality and Social Psychology Review, 6(6), 283-294.

Simon, D., Snow, C.J., \& Read, S.J. (2004). The redux of cognitive consistency theories: evidence judgements by constraint satisfaction. Journal of Personality and Social Psychology, 86(6), 814-837. 
Strandvik, T., Holmlund, M., \& Edvardsson, B. (2012). Customer needing: a challenge for the seller offering. Journal of Business and Industrial Marketing, 27(2), 132-141.

Strandvik, T., Holmlund, M., \& Grönroos, C. (2014). The mental footprint of marketing in the boardroom. Journal of Service Management, 25(2), 241-252.

Strauss, A., \& Corbin, J. (1998). Basics of Qualitative (2 ${ }^{\text {nd }}$ Ed.). London, UK: Sage.

Tasselli, S., Kilduff, M., \& Menges, J. (2015). The microfoundations of organizational social networks: a review and an agenda for future research, Journal of Management, published early online: 1-27 DOI:10.1177/0149206315573996

Thibaut, J.W., \& Kelley, H.H. (1959). The Social Psychology of Groups. New York: John Wiley.

Tsai, W., \& Ghoshal, S. (1998). Social capital and value creation: the role of intrafirm networks. The Academy of Management Journal, 41(4), 464-476.

Todorova, G., \& Durisin, B. (2007). Absorptive capacity: valuing a reconceptualization. Academy of Management Review, 32, 774-786.

Volberda, H., Foss, N., \& Lyles, M. (2010). Absorbing the concept of absorptive capacity: How to realize its potential in the organization field. Organization Science, 21(4), 931951.

Weick, K. (2006). The role of imagination in the organizing of knowledge, European Journal of Information Systems, 15, 446-452.

Yin, R.K. (1994). Case study research: design and methods. London: Sage. 